\title{
Agricultural Statistics: Using Multiple Modes of Food Crops Data Collection In Indonesia During The Covid-19 Pandemic
}

\author{
Ratna Rizki Amalia \\ Badan Pusat Statistik, ratna.amalia@bps.go.id
}

and effective management in the planning, monitoring, and evaluating government policy [3].

During this time, food crops data collection was carried out using conventional methods, namely direct measurements in the field and direct interviews (face-to-face interviews) with respondents. However, since the government officially announced the COVID-19 case in early March 2020, and then followed by several new policies such as the Large-Scale Social Restriction (PSBB) policy in some regions in Indonesia, it automatically affects the agricultural data collection process carried out by BPS.

Spreading pandemic has blocked this avenue for gathering data precisely at a time when data are most needed. The pandemic challenges to accessing communities and collecting data will impact all stakeholders relying on up-to-date data for response and planning, including national governments and international and national organizations. Therefore, BPS that works on primary food crops data collection must look for alternatives to surveying with deadlines to get fast and accurate data.

This paper discusses the issue of collecting statistical data on food crops in the COVID-19 era. The discussion focused on the methodology and business process of the data collection, the challenges faced, and policy recommendations related to Indonesia's agricultural data collection, especially during this pandemic.

\section{LITERATURE REVIEW}

Data collection is an essential component to conduct a research/evaluation. The researcher should be able to access the data that needs to be collected for the study. The methodology is influenced by the data collection strategy, the type of variable, the accuracy required, the collection point, and the enumerator [4].

COVID-19 is impacting the collection of food crops data in various ways. The restrictions 
necessary to combat COVID-19 are creating a massive obstacle to standard data collection approaches and operations, precisely when there is a massive increase in demand for information. Furthermore, the situation is rapidly evolving, making regular planning impossible. The typical impact is the need to suspend data collection through face-to-face interviews [5].

Producing representative, disaggregated, agreedupon, and up-to-date data is challenging. Producing representative, disaggregated, and agreed-upon data on internal displacement is involved in protracted crises and even more so in emergencies [6]. One of the methods recommended by the World Bank to collect statistical data during the COVID-19 pandemic is a phone survey. Phone surveys do not require face-to-face interactions, so highly suited for data collection in emergencies. Moreover, they could collect information from respondents rapidly and at a low cost. These methods also offer flexibility to alter sampling or questionnaire to response to evolving information needs [7].

\section{METHODOLOGY}

Indonesia's vast territory with various social, economic characteristics and policies between regions related to the COVID-19 pandemic has caused a dilemma in choosing the best alternative method for collecting statistical data on food crops throughout Indonesia. To respond to this situation, BPS tries to find alternative ways to collect agricultural data in this Pandemic COVID-19 era. Before determining the appropriate data collection method during this pandemic, BPS first conducts a risk analysis.

This risk analysis process follows FAO guidance to manage and conduct evaluations during international and national COVID-19 crises and restrictions. Risk analysis includes an analysis of risks to the people involved in the survey, the quality and timeliness of the work, and the organization [8].

As a form of implementation, BPS identifies areas affected by COVID-19. Each BPS regional office carries out the process of identifying regional emergencies. The area's emergency identification is divided into four zones: the green zone, yellow zone, orange zone, and red zone. Green Zone is an area with no confirmed cases, or without any infected travelers arriving from other countries/regions; the yellow zone is an area with few cases of local transmission, but without community transmission groups; the orange zone is the area adjacent to the Red Zone or with small groups, and the red zone is the area with community transmission. Then, the BPS regional offices choose how to survey each of its districts according to the emergency conditions and local government policies related to the COVID-19 Pandemic. This identification process is carried out on an ongoing basis, adjusted to the development conditions of the COVID-19 case and regulations in each region.

Furthermore, identifying each area was sent to the BPS central office as the basis for preparing a budget plan, making sampling methods, and preparing standard operating procedures for food plant data collection during the COVID-19 pandemic.

\section{DISCUSSION}

\section{Collection of Agricultural Statistics Data in Indonesia before Pandemic}

BPS-Statistics Indonesia officially carries out the collection of statistical data on food crops in Indonesia. The primary data collected is plant area data (including planted area, harvested area, and damaged area) and productivity as a component of food crop production data. The food crops covered include paddy (lowland paddy and dryland paddy) and secondary crops (maize, soybeans, peanuts, cassava, and sweet potato).

BPS conducted a direct observation of the rice growth phase in the field using the Area Sampling Frame (ASF) method. Technically, the enumerator will visit the observation point in the selected sample segment, observe the rice growth phase, and capture it using a smartphone equipped with an Android application. Then, the surveyor sent the observation result to the server using an internet connection. The final output is the paddy field area's estimation according to the growth phases, namely land preparation, vegetative 1 , vegetative 2 , generative, and harvest. Data collection using the ASF method is carried out every seven days last every month. 
For secondary food crops, plant area is collected through Agricultural Statistics (SP) activities under the coordination of the Ministry of Agriculture using several conventional approaches such as the use of seeds, use of water for irrigation (irrigation blocks), information from farmers and village officials, and observation with eye-estimate [9]. SP data collection is carried out regularly every month by the Head of the Service Branch or "Mantri Tani" by compiling village-level data covering all subdistricts in the Republic of Indonesia and reported with the SP-List [10].

Meanwhile, the data collection of food crop productivity was carried out using the Crop Cutting Survey based on the household-survey. The surveyor will harvest and measure the plants' weight on the selected sample plots and then conduct direct interviews with farmers that cultivated the paddy fields to obtain supporting information such as the seed varieties used, fertilizer, and pest attack.

\section{Alternative Ways to the Food Crops Data Collection during Pandemic}

In collecting statistical data on food crops, BPS uses a combination method. It is because of differences in the status of areas affected by COVID-19 and different policies between regions in each province, and even at the regency or sub-district level, it can vary. Besides, data collection using a combination method is also expected to reduce the potential for statistical bias. BPS's alternative survey methods to collect statistical data on food crop agriculture include direct field observation and measurement, socially distanced face-to-face interviews, and telephone interviews.

\section{Measurement and direct observation in the field}

Data collection on plant productivity and harvest area can be done by direct measurement and observation if the area in the regency is still in the green or yellow zone, and there is no lockdown policy so that surveyors can still enter the area and take direct measurements. In this direct measurement or observation process, surveyors can measure the productivity or phase of growth of food crops in paddy fields without interacting directly with farmers. However, during this pandemic, measurement and observation cannot be carried out immediately, just like before the pandemic. Residents' concerns about surveyors who had just come to their area during this pandemic were also an obstacle faced by several surveyors who collected data in the field. Therefore, good communication with the regional head and residents was also carried out to inform the survey's implementation.

\section{Physically Distanced Face-to-Face Interview}

The socially distanced face-to-face interview method can be carried out for areas that do not carry out large-scale social restrictions or lockdowns so that surveyors can still enter the sample areas and interview sample households. A socially distanced face-to-face interviews were conducted for respondents whose locations were close/easy to reach by officers, and if operational, the implementation was more accessible than interviews by telephone.

In its implementation, surveyors maintaining a distance (at least 1 meter) from respondents during the interview process and do not make direct contact with respondents such as a handshake. Besides, they must pay attention to health protocols during the COVID-19 pandemic to ensure they are protected, such as wearing masks, wearing long sleeves, washing hands thoroughly between interviews, and ensuring that officers are not sick when conducting interviews. When using this interview method, all questions are asked directly to the respondent, namely farmers who cultivate food crops. Questions regarding the productivity of food crops previously measured by crop cut experiments were answered with an approach to yield weight information and information on farmers' land area.

Attempts were made to conduct interviews during this pandemic as effectively and efficiently as possible to shorten the time and minimize contact or interaction with respondents. Therefore, the interview process must be carried out as effectively and efficiently as possible. However, this is not easy to do if it still uses the questionnaire used so far in direct 
interviews because it is long with many questions. In general, the interview process for collecting productivity data using a questionnaire takes 30 minutes to about 1 hour. Therefore, the elaborately structured questionnaires currently used in the food crops data collection will need to be adapted significantly to fit within a 10-15minute acceptable timeframe for the brief interview. To overcome this, BPS reviewed the existing questionnaire to determine the core questions that need to be asked in the interview process. Based on the review results, the Crop Cutting Survey Questionnaire for collecting food crop productivity data, which previously consisted of 4 pages, was summarized into 1 page. Despite the simplification, the leading information regarding productivity is still included. Information collected through a simplified interview questionnaire includes harvest month, land type, variety, harvested area, yield weight, the impact of pests (whether heavy, moderate, or mild), whether affected by climatic phenomena such as floods and drought and comparisons productivity with the previous period (higher or lower).

\section{Interview by telephone}

Another alternative way of collecting data on food crops during the COVID-19 pandemic is by telephone interviews. This method is recommended by ILO and FAO for data collection during this pandemic by looking at each country's conditions. One of the significant challenges in conducting this phone survey is the unavailability of a database for agricultural household cell phone numbers. Therefore, BPS tries to build a database of contact details of the agricultural household. BPS has used several methods to build this database by collecting information from previous agricultural surveys and information from other BPS surveys BPS. Besides, survey officers also collect cellphone number information from other sources, such as asking relatives or neighbors in the household. Moreover, in its implementation, telephone surveys must also consider the questionnaire used. Therefore, just as in distance interviews, phone-mode interviews also use a reduced questionnaire. Besides being more efficient, the use of the questionnaire is also expected to reduce the respondent burden.

\section{Issues of The Data Collected}

Although most of the problems related to the implementation of field activities, another challenge that was also faced was the accuracy of the data collected through this combination survey method. Potential biases are introduced by the shift in methods and budget in time. Data compilers across many countries are trying to deal with the impacts and maintain data flow [7]. Data quality dimensions (data, data use, and data collection process) need to be assessed [11]. FAO defines quality in statistics as the degree to which its statistical outputs fulfill requirements, and the following quality dimensions are taken into account relevance of data; accuracy and reliability; Timeliness and Punctuality; Coherence and Comparability [12].

We conduct editing and data validation for each data collected using different collection modes to ensure the data quality. Editing and data validation are essential components of generating high-quality indications at every step of the survey process. The data compilation process started from the district, provincial, and until the national level. The analysis process is conducted to review the survey data to understand the current estimate, explain the relationship to the related or historical data, and identify outliers. If we found any outliers from the data, so we verify the reported data, and if an error is found, so we correct it.

For verifying the estimation result, we also compare the estimation result with other data, such as the price, the consumption, the climate, and the natural disaster information from various sources. Furthermore, the verification process is also carried out by comparing the estimated data with the information obtained from the satellite imagery data being developed by BPS. Linking up with non-traditional data will be a crucial element to support timely analysis and fill information gaps.

\section{CONCLUSION}

This paper discusses the implementation of multi-mode in collecting food crops data in the 
Pandemic COVID-19 era. The survey combines measurement and direct observation in the field, physically distanced face-to-face interviews, and phone interviews. The main challenge in implementing the new method, especially phone interview, is the unavailability of a database containing information on the respondent's telephone number. To address this issue, BPS is trying to compile a database of agricultural household telephone numbers collected from several sources.

Strategic and long-term thinking is needed to account for the lack of data from this current period and the future. National statistics data cannot depend forever on traditional data collection. Technology that is rapidly developing in society, such as communication via telephone or email, can be a reasonably efficient medium for collecting remote data. Good frame construction, sampling methods, and appropriate data collection methods are needed to produce useful data.

\section{CONFLICT OF INTEREST}

The views expressed in this information product are those of the author and do not necessarily reflect the views or policies of BPS-Statistics Indonesia.

\section{REFERENCES}

[1] BPS-Statistics Indonesia. (2018). Laporan Perekonomian Indonesia 2020 [Indonesian Economic Report, 2020]. Jakarta: BPS-Statistics Indonesia.

[2] Kadir, K. \& Amalia, R.R. (2016). Economic Growth and Poverty Reduction: The Role of the Agricultural Sector in Rural Indonesia. Proceeding on ICAS VII Seventh International Conference on Agricultural Statistics. DOI: 10.1481/icasVII.2016.03

[3] Bresciani, F. \& Valdés, A. (2007). Beyond Food Production: The Role of Agriculture in Poverty Reduction. Rome: FAO Rome.

[4] FAO. (1999). Guidelines for the Routine Collection of Capture Fishery Data. FAO fisheries technical paper 382.

[5] ILO. (2020). COVID-19: Guidance for Labour Statistics Data Collection.
Retrieved September 11,2020 from: https://www.ilo.org/wcmsp5/groups/publi c/---dgreports/---

stat/documents/publication/wcms_74114 5.pdf

[6] Welsch, W. (2020, May 5). The New Normal: Collecting Data Amidst A Global Pandemic. Retrieved September 14, 2020, from

https://www.jips.org/uploads/2020/05/JIP

S-TheNewNormal-

CollectingDataAmidstPandemic-

May2020-min.pdf

[7] World Bank. (2020). High Frequency Mobile Phone Surveys of Households to Assess the Impacts of COVID-19: Overview (English). Washington, D.C.: World Bank Group. http://documents.worldbank.org/curated/e $\mathrm{n} / 703571588695361920 /$ Overview

[8] FAO. (2020). Risk analysis and guidance for the management and conduct of evaluations during international and national level COVID-19 crisis and restriction. OED Guidelines Series 05/2020. FAO Rome.

[9] Kadir. (2019). Memperbaiki Data Pangan Indonesia lewat Metode Kerangka Sampel Area [Improving Indonesian Food Data through the Area Sampling Frame Method]. Jakarta: Center for Indonesian Policy Studies.

[10] Kementrian Pertanian \& Badan Pusat Statistik. (2015). Pedoman Pengumpulan Data Statistik Pertanian Tanaman Pangan [Guidelines for Collecting Data on Agricultural Statistics for Food Crops]. Jakarta: Badan Pusat Statistik.

[11] Chen, H., Hailey, D., Wang, N., Ning \& Yu, P. (2014). A Review of Data Quality Assessment Methods for Public Health Information Systems. International Journal of Environmental Research and Public Health. Int. J. Environ. Res. Public Health 2014, 11, 5170-5207; DOI: 10.3390/ijerph 110505170

[12] FAO. (2014). The FAO Statistics Quality Assurance Framework. FAO Rome. http://www.fao.org/3/i3664e/i3664e.pdf 